\title{
The Benefits of Implementation of Biometric Attendance System
}

\author{
G. M. MIR ${ }^{1 *}$, A. A. BALKHI ${ }^{2}$, N. A. LALA ${ }^{2}$, N. A. SOFI', \\ M. M. KIRMANI ${ }^{3}$, ITFAQ A. MIR ${ }^{1}$ and H. ARIF HAMID ${ }^{1}$ \\ ${ }^{1}$ Agricultural Research Information Sysetm, SKUAST-K, India. \\ ${ }^{2}$ College of Agricultural Engineering, SKUAST-K, India. \\ ${ }^{3}$ Faculty of Fisheries, SKUAST-K, India.
}

\begin{abstract}
Biometric technology is now used for employees time management attendance system because it has ability to recognize peoples unique physiological characteristics. Because of multiple benifits of Biometric attendance system it has gained high popularity in the market. Biometrics attendance system is extremely useful in helping business community feel secure by eliminating employees time theft, as it relies on ones personal characteristics that vary between individuals. Since biometrics characteristics cannot be duplicate, it prevents punching on behalf of a co-worker working in the same company. The manual practice of attendance system is time consuming and needs full time personal monitoring whereas biometric attendance saves employee time, decreases staffing overhead and provides accurate labour data to payroll system to effectively manage business operations and thereby increase productivity. Moreover the biometric attendance system has brought transperancy and enhanced the work culture in the system. We will explore various advantages and disadventages of implementation of the biometric attendance system to a big organization, or small entrepruner or unit and the necesary measures for its efficient implementation.
\end{abstract}

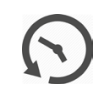

Article History

Received: 26 February 2018

Accepted: 22 March 2018

\section{Keywords}

Attendance, Biometric characteristics, Employee, Face recognition, Iris.

\section{Introduction}

An employee is being engaged by an organization as per requirement on substantial or contractual basis. He/She is monitored for his/her assignments by the officer incharge. The biometric machines read personal fingerprint, iris, hand shape or face shape and ensure that employees cannot punch in for one another, thus preventing employee time theft. The ease of operation and the individual identification of employees has popularized the technology

CONTACT G. M. Mir mir.aspengg@gmail.com 9 Agricultural Research Information Sysetm, SKUAST-K, India.

(C) 2018 The Author(s). Published by Oriental Scientific Publishing Company

This is an 6 Open Access article licensed under a Creative Commons Attribution-NonCommercial-ShareAlike 4.0 International License (https://creativecommons.org/licenses/by-nc-sa/4.0/), which permits unrestricted NonCommercial use, distribution, and reproduction in any medium, provided the original work is properly cited.

To link to this article: http://dx.doi.org/10.13005/ojcst11.01.09 
delivering many benefits. The biometric attendance system for administration and academic institutions has been presented in ${ }^{1-3}$. The high market attraction has increased job evenues in the market for its effective implementation. The virtual environment for biometric technology evaluations and experiment design has been reported $\mathrm{in}^{4}$. An employee attendance through the biometric machine installed at convenient locations throughout the organization or company. The biometric data of employees is fed into the biometric device and this data is then used as reference for authenticating the right employee for mariking attendance on the device. At the time of marking attendance through machine, once the exact match with already fetched data is obtained the arrival and departure times for employees are registered. A review of biometric technology along with trends and prospects related to pattern recognition is reported $\mathrm{in}^{5}$. All the attendances of employees can be monitored on realtime basis or can be retreived from the device at the end of month. In case of realtime basis all the machines are terminated to a computer system acting as biometric server controlled by software. The admin control is with the boss of organization or a company. $\mathrm{He} / \mathrm{She}$ can provide access to any employee with limited privileges.

\section{Benefits}

The biometric time attendance system being accurate, marking ones attendance on individual basis has adventages of self generating summary reports on monthly, daily or annual basis ${ }^{6}$. The physiological atributes cannot be duplicated or forged, a coworker cannot mark attendance for any other employee. Managers and supervisors have gained confidence for tracking the employees time management system. The problem of time lost by Compnies for calculating the amounts of total working hours each year for their absenties and late reporting of employees is saved by automatic calculation by machine itself. The use of biometric attendance system through internet connectivity enables employer to monitor employees working at remote locations, even if they are half way around the world ${ }^{7}$. The morale and enthusiasm of employees working extra time in any company without extra provileges gets damaged because of non availability of system for calculating extra time put in by employees. The biometric machines enable supervisors to capture extra time of employees and reward accordingly. The biometric attendance system eliminates the concept of time theft and increases productivity. The direct benefit to the raising productivity rates is raising profits while minimizing labor costs. By increasing productivity the rates of product will definitely be reduced eventually resulting in the benifit of consumers. The poor tracking practices of employees is eliminated and data available with biometric time attendance system creates a transparent and concrete audit trial for attendance and time records. The mproved accountability and transparency enhances the work culture with adaptation of employees to the system. The accuracy of time management about who is late is a sigh of relief to the working and dedicated employees.

\section{Implementation of BAS}

The manual atendance system can be manupulated by the welwisher and in many cases attendance of many days can be marked at any time. The proxy attendance has made the official work lazy and unproductive. This is either because of loose administration or laging ones consience. The BAS on the other hand is maintaining time based digital attendance is probably a virtual force for upscaling the workculture in any orgnisation/system. Since the data bases fed into the system can not be duplicated, so the presence of concerned employees is surely ensured, which can be monitored by a single person. Unless the Administration/Management enforces BAS at the time of disbusememnt of salaries of employees the BAS will not be much effective.

\section{Fuzzy logic for Biometric Atendance}

Fuzzy logic is flexible and is employed to handle the concept of partial truth, where the truth value may range between completely false, in contrast to Boolean logic, where the truth values of variables may only be the integer values of 0 or 1 . The variables in mathematics usually take numerical values, the Fuzzy logic accepts linguistic variables such as, very cold, cold, warm, hot, very hot etc. Fuzzy logic control system is widely used in control system engineering. Alhough alternate approaches such as neural networks and genetic algorithm are available for problem solving in many cases, the fuzzy logic approach has adventage of its simplicity of applying linguistic variables. The linguistic variables 
are used to formulate rules by incorporating IF and THEN conditions which finally decides the design of controller. The biometric technology using fuzzy logic decision making has been reported in ${ }^{8}$. Fuzzy controllers are simple having three main stages as input stage, processing stage and output stage. The input stage is of variables of intrest the conditional combination of which is required to generate output. The processing stage invoks apropriate rule and generate a result for each then combines results of the rules. The processing stage is based on the collection of logic rules in the form of IF-THEN statements. The IF part is called the "Antecedent" and the THEN part is called the "Consequent" the typical fuzzy control system has dozens of rules. Figure 1 depicts the fuzzy logic block diagram of biometric attendace syetm for enhancing the work culture in Organization/Company/System. Three variables manual attendance, biometric attendance and implementation are fed into the fuzzifier. Based on the rule base these three variables are evaluated by Mamdani inference engine for effectiveness with respect to each other in response to various membership values. The results are fed to defuzzifier which finally gives the relationship between input variables for yielding the effective end result.

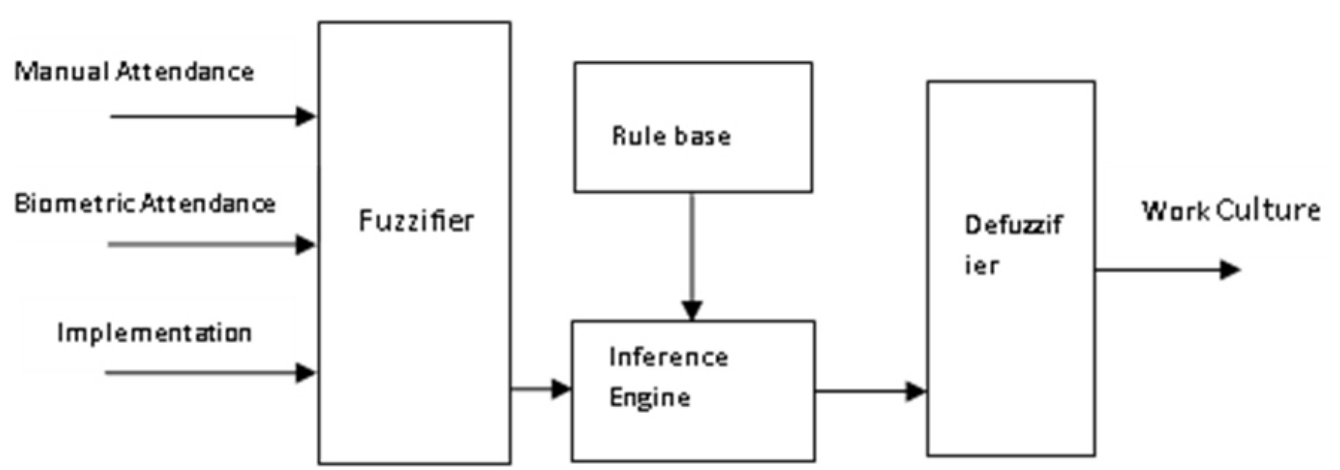

Fig. 1: Block diagram for relationship between variables

The three dimensional view of simulation results obtained are depicted in Figure 2(a) and 2(b).

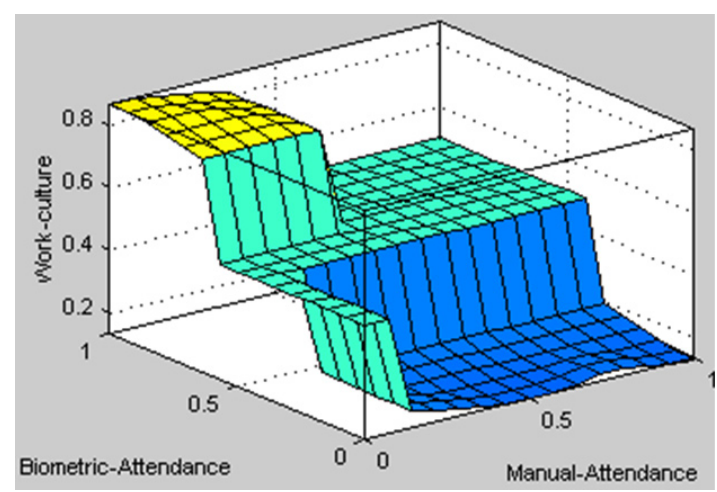

Fig. 2(a) Relationship between Biometric attendance, Manual attendance and Work culture
Figure 3 gives the insight view of the effect of Biometric attendance with Implementation on Work culture

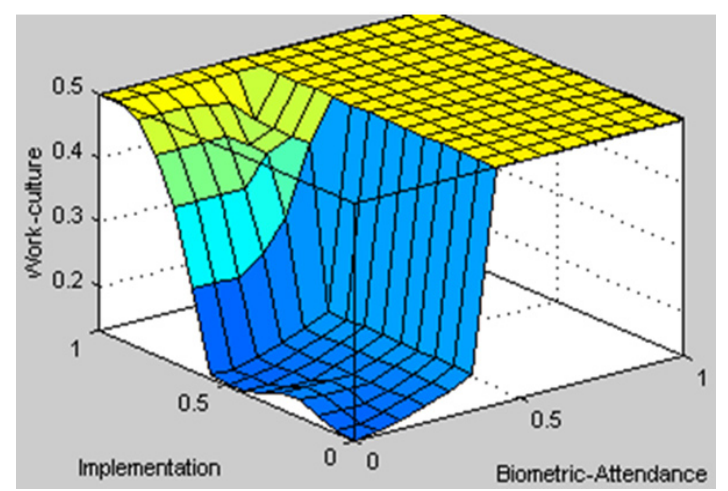

Fig. 2(b) Relationship between Biometric attendance, Implementation and Work culture 


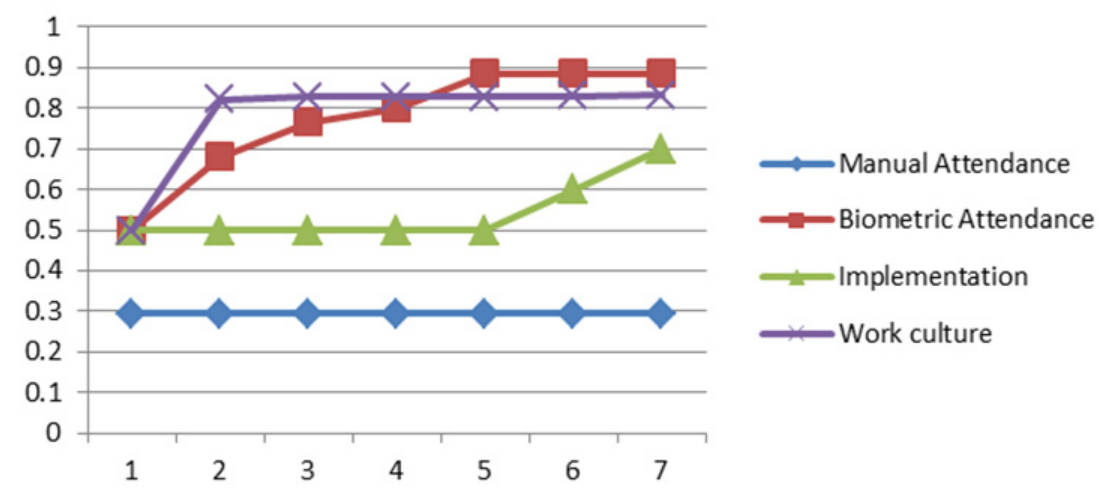

Fig. 3: Effect of Biometric attendance with Implementation on Work culture

\section{Results and Discussion}

The graphical reports of biometric attendance of one of the Colleges for last one year retrieved from Biometric Attendance System are given in Figure 4. The graphical results give a clear insight about the variables of interest. The graphical results reveal that attendance percentage is high for the last three months, because the administration has monitored digital attendance for these months. Although some employees are on study leave and earned leave so the actual absent percentage will be lower by around 7 to $8 \%$. The absentees have considerably reduced although late coming and early going seems to be habitual with some employees and needs improvement which is possible only by forced implementation.
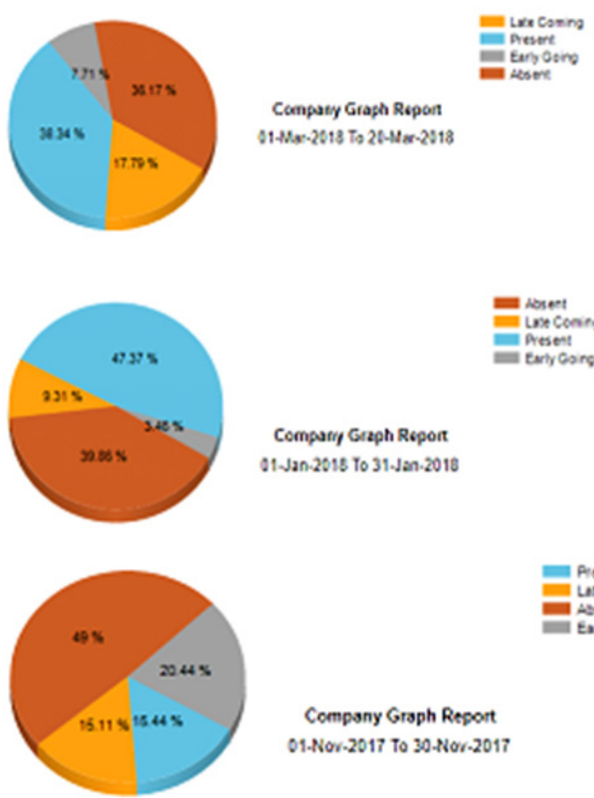

Company Graph Report 01-Nor-2017 To 30-Nor-2017
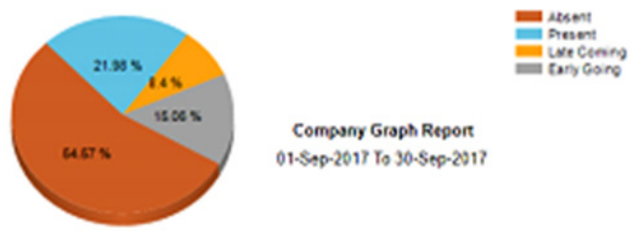

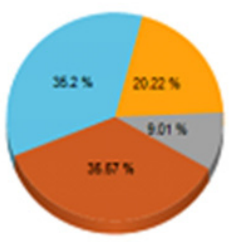

Compuny, Graph Report 01-Fab-2018 To 28 - ob-2018

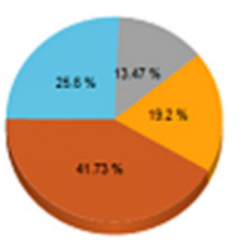

Compary Geoph Resort 01.Duc-2017 To 31-Dv6-2017

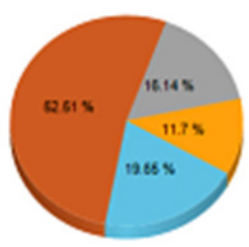

Company Graph Repont 01-0ct-2017 To 31-Cet-201?

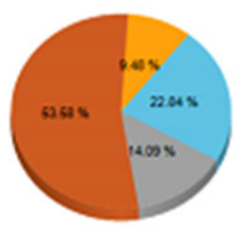

Company Geaph Reson 01-sus-2517 To 32-Jus-201? 

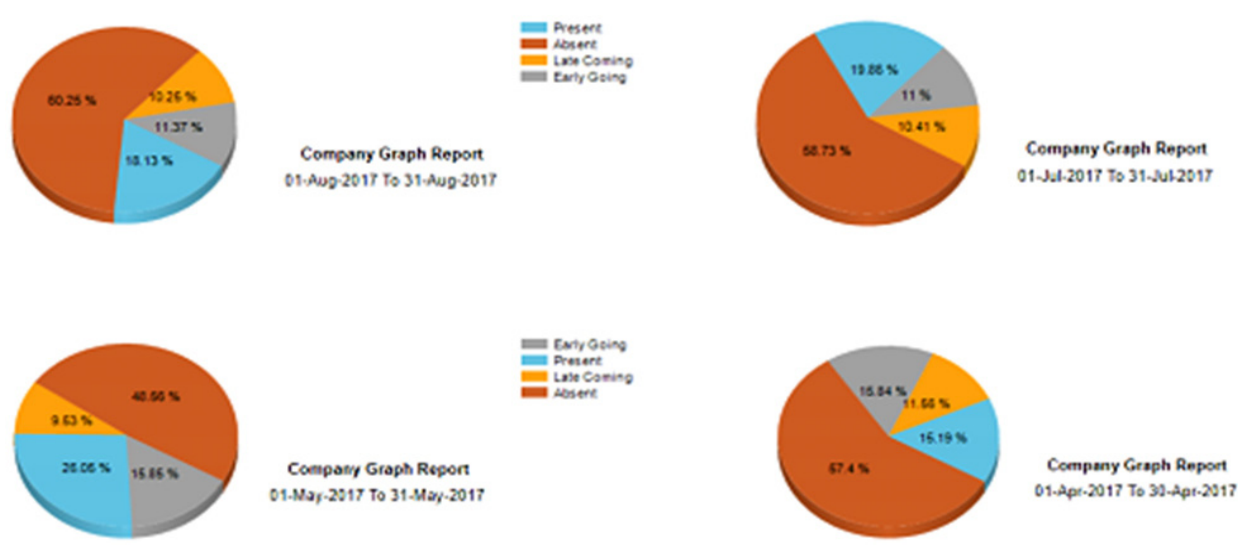

Fig. 4: Graphical data of Attendance of college for last one year

\section{Conclusion}

No doubt employees are bound to perform their duties for their organisations because they are being paid for their respective works, but because of their personal engagements and liabilities some employees are taking liberties in response to the situation/environment they are working in. The only way left to engage these employees is to increase their monitoring which can be easily maintained by incorporation of biometric attendance system. The biometric attendance machines records punches of the employees and calculates the total working hours of employees which can be used for disbursement of salaries.

\section{References}

Eze S. G and Chijioke E. O, "Public Enlightenment Education on the Acceptance of Fingerprint Biometric Technology for Administration in Academic Institutions and other Organizations", Journal of Education and Practice, 2016, 7(28), pp-158-163. Adewole K. S, Abdulsalam S. O, Babtunde R.S, Shittu T. M and Oloyede M. O, "Development of Fingerprint Biometric Attendance System for Non-Academic Staff in A Tertiary institution", 2014, 5(2), pp-62-70.

3 Cappelli R, Ferrara M, Franco A and Maltoni D, "Fingerprint Verification Competition" Biometric Technology Today, 2006, 15(7), pp-7-9.

4 Labati R. D, Genovese A, Piuri V and Scotti F, "Acurate 3D Fingerprint Virtualenvironment for Biometric Technology Evaluations and Experiment design", Computational Intelligence and Virtual Environments for Measurement System and Aplications, 2013, IEEE International Conference pp-43-48.
Prospects", Pattern recognition, 2014, 47(8), pp-2673-2688.

6 Davies S. G, "Touching Big Brother: how Biometric Technology wil Fuse Flesh and Machine", Information Technology and People, 2016, 7(4), pp-38-47.

Akhmetov B, Doszhanova A, Ivavov A, Kartbayev $\mathrm{T}$ and Malygin A, "Biometric technology in Securing the Internet using Neural Network Technology", Procedings of World Academy of Science Enginering and Technology, 2013, No. 79, P-2046.

Kumar S. S, "Multimodeal Biometric Technology using Fuzzy Logic decision and Fuzzy Inference System", Asian Journal od Computer Science and Technology, 2016, 5(2), pp-1-4.

9 Byun S and Byun S. E, "Exploring Perceptions toward Biometric technology in Serviceen Counters: A Comparision of Curent users and Potrential Adopters", Behaviour and Information Technology, 2013, 32(3), pp-217230. 